\title{
The Effect of Water Salinity and Radiation Intensity to the Temperature Distribution and Evaporation Rate inside Porous Media
}

\author{
Nova Risdiyanto ISMAIL*, Sudjito SOEPARMAN, Denny WIDHIYANURIYAWAN, Widya WIJAYANTI
}

\begin{abstract}
In the coastal areas, there are found many cases of clean water crisis; the most reasonable solution is to use the solar still from salty seawater. Sea salt concentration levels vary widely in each region depending on ecological conditions and materials carried by the river. This study aims to analyze the effect of salinity and radiation intensity towards the evaporation rate. Several parameters, such as the difference in the mass of the specimen, surface temperature, and evaporation rate were observed. The evaporation rate data shows that concrete with ferrous sand aggregate (particle size of $0.125 \mathrm{~mm}$ ) has the highest value in which the thermal conductivity value of this specimen is of the highest value as well. Higher salt addition and radiation cause the temperature value that each specimen generated to become higher. Therefore, the FS125, which is concrete with $0.125 \mathrm{~mm}$ ferrous sand aggregate, has the best capability of porous media in the absorbent plate of solar still application.
\end{abstract}

Keywords: evaporation rate; porous media; radiation; saltwater

\section{INTRODUCTION}

People in the coastal areas of Indonesia often experience a shortage of clean water, especially during the dry season. The potential use of solar still in technology is very large due to the presence of abundant seawater and solar radiation resources. It is supported by the fact that the geographical location of the State of Indonesia is on the equator. Efforts to increase the performance of solar still need to be developed. One of the main components in solar still is the absorbent plate. This component serves to channel the energy of solar heat absorbed by the seawater. The heat obtained from the absorbent plate is used to convert seawater into water vapor. The productivity of solar still depends on the amount of seawater that can be evaporated. Efforts to improve the efficiency of heat transfer in the absorbent plate have been extensively investigated. One of them is by using the addition of material in the form of porous media on the absorbent plate. The seawater that enters the empty cavities of the porous medium has a thin layer. The contact area of seawater with porous media is increasing, so that the heat transfer process occurs faster. Several types of materials have been studied for use as additional material of the absorbent plate. The addition of cotton fabric over an absorbent plate can increase the productivity of condensate water $[1,2]$. A threefold increase was obtained by using a wick added on top of the absorbent plate [3-5]. This study proposed stone and concrete as absorbent plate materials. They are non-metallic, so there is no risk of corrosion. In addition, the thermal conductivity value of those materials is relatively higher when compared with other porous media materials, such as fabrics and sponges.

The evaporation process in porous media is a complex phenomenon involving heat transfer, mass and phase change. This phenomenon can be found in several natural occurrences as well as technical applications such as soil evaporation, drying of agricultural produce, geothermal reservoirs, drying of textile products, etc. [6, 7].

The fluid that is used in solar still applications is seawater. One of the properties of seawater is salinity, i.e. the percentage of salt content that can be crystallized in a certain volume of seawater. In its application to the installation of a solar still, the condition of seawater filling occurs continuously. The volume of seawater in the basin is kept constant. When there is continuous evaporation, there are two possible things that happen to the salt content. The first possibility is the salt content is released from the bonded $\mathrm{H}_{2} \mathrm{O}$ solution, looking for other $\mathrm{H}_{2} \mathrm{O}$ couples still in the liquid phase. The level of the salt content of seawater in the basin is increasing due to the specific bonding reaction $[8,9]$. The second possibility is that the salt content which does not get the $\mathrm{H}_{2} \mathrm{O}$ pair in the liquid phase forms a precipitate of salt crystals. The increase of salt content in seawater and salt crystalline formation is likely to cause changes in heat transfer that occurs.

Aqueous solutions with higher salt concentration conditions may cause the evaporation process to become more inhibited. The chemical potential of the ionic bonds of salt from water is resulting in a lower salt vapor pressure $[10,11]$. A study using a cup containing saline solution with a specific salinity indicates that the higher the salinity, the lower the evaporation rate $[12,13]$. However, the crystallized salt has a reasonably low $C_{p} \mathrm{NaCl}$ value of $0.853 \mathrm{~J} /(\mathrm{gK})$ to accelerate the rise in temperature at the same amount of energy.

In solar still applications, several studies suggest a separate reservoir of salt collectors. So along with the evaporation, salt concentration in seawater in the basin is not getting higher. The addition of spherical salt storage space can increase productivity over conventional solar still due to the storage of heat by salt [14]. Other studies have also shown that the process of distillation of saltwater is more productive at higher salinity of seawater [15].

The research proposes to investigate porous media as an absorbent plate, which, in addition to causing a thin layer of fluid, can also be a crystallized salt reservoir. The purpose of this research is to analyze the influence of salt and radiation levels to the evaporation rate that occurs on the porous media of stone and concrete.

\section{MATERIALS AND METHODS}

The research uses experimental study by observing several parameters. Several types of concrete and stone materials were selected to observe the effect of this type of 
material. The concrete specimens are divided into two types based on the selection of sand types as fine aggregates. The use of river sand and iron sand as the fine aggregate is observed to obtain the good type of material to be used. In addition, the grain size of each aggregate varied between $0.125 \mathrm{~mm}$ and $0.250 \mathrm{~mm}$. The composition of the cast concrete on each specimen is 1 cement: 2 sand. Natural stone specimens were used as comparative materials given that the pores or drain cavities on natural stone are formed naturally other than concrete. Natural stone used is a black stone from the foot of Mount Arjuno, East Java; it is often used as the basic material for making temples and traditional cooking utensil called cobek. The following specimen data is used in this study. All specimens used were formed with the dimensions of $50 \times$ $10 \times 100 \mathrm{~mm}$. The specification of five experimental specimens is shown in Tab. 1.

Instead of using seawater, a mixture of $\mathrm{NaCl}$ solutions was used with various variations of salinity. The amount of salt content is determined by using the mass percentage between the salt and water mixture as the solvent. The salt content studied included $0 \%, 3.5 \%, 7 \%$ and $10.5 \%$ of salt mass fractions. The usual seawater salinity is about $3-5 \%$. Fig. 1 shows the installation of the apparatus in this experiment.

In the experiment, the source of radiation uses the incandescent lamp instead of solar radiation. High radiation beam light is regulated by using an incoming voltage regulator. The position of the lamp was arranged in a way as seen in Fig. 1. The direction of the incident angle of light is $30^{\circ}$. The amount of energy of light is obtained by using the pyranometer at the same distance and position to the specimen. Therefore, the value of radiation $\left(\mathrm{W} / \mathrm{m}^{2}\right)$ from the beam of light at each voltage change is obtained. The variations of input voltage used in this study were $220 \mathrm{~V}, 200 \mathrm{~V}, 175 \mathrm{~V}, 150 \mathrm{~V}, 125 \mathrm{~V}$ and $100 \mathrm{~V}$ with radiation values at each voltage variation of $508.21 \mathrm{~W} / \mathrm{m}^{2}, 415.07$ $\mathrm{W} / \mathrm{m}^{2}, 325.94 \mathrm{~W} / \mathrm{m}^{2}, 250.11 \mathrm{~W} / \mathrm{m}^{2}, 178.27 \mathrm{~W} / \mathrm{m}^{2}$ and $114.41 \mathrm{~W} / \mathrm{m}^{2}$, respectively.

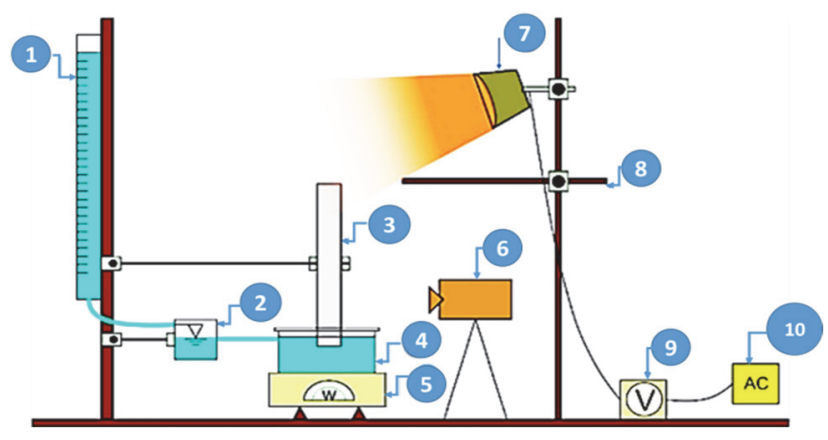

Figure 1 Experimental apparatus

Where:

1. Saltwater reservoir

2. Float valve

3. Porous media specimen

4. Saltwater basin

5. Mass measuring instrument

6. Camera

7. Incandescent lamps

8. Radiation boundary control

9. Voltage regulator

\section{AC power source}

The specimen is placed in a container of clear glass material with a pedestal on its base. Saltwater from the reservoir in the form of a measuring cup is set to remain at a constant height of $1 \mathrm{~cm}$ from the bottom of the underside of the specimen by using a float valve. Therefore, even if the water in the container is absorbed by the specimen and evaporates, the amount of water in the pond will always stay at a fixed altitude. The water level is set to keep staying $1 \mathrm{~cm}$ from the underside of the specimen. Therefore, the area of water is $5 \times 1 \mathrm{~cm}^{2}$. By using a measuring cup for the reservoir, the amount of water entering the pond will be detected.

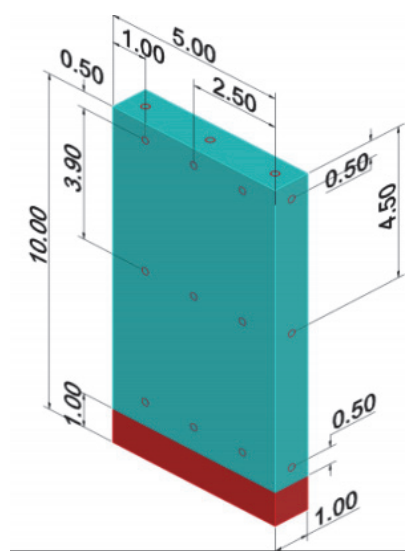

Figure 2 Thermocouple location for temperature distribution data collection

Temperature values are taken at some points by using thermocouple type $\mathrm{K}$. The location of the temperature sampling point appears, as shown in Fig. 2.

Data retrieval is done for 2 hours in each variation. Some parameters include temperature value at some point of specimen surface location, ambient temperature, basin water temperature, change of initial and dried final mass of the specimen, and reduced water volume in the reservoir.

Temperature data is processed by using color plots to determine the temperature distribution on the surface of the specimen. Porosity data is taken in several stages. Each specimen has the same $(V)$ volume i.e. $50 \mathrm{~cm}^{3}$ or $50 \times 10^{-6}$ $\mathrm{m}^{3}$. Each specimen is heated in an oven with temperature $\pm 100{ }^{\circ} \mathrm{C}$ for 24 hours, and then the $m_{d r y}$ mass data is taken. This step aims to find the dry mass of the specimens in which each specimen is attempted to have a moisture content of $0 \%$. The soaking process is conducted with water medium for 24 hours, and then mass data from each specimen is taken. This process is done to look for the wet mass $\left(m_{w e t}\right)$ specimen. Water that fills the porous media has a density $\left(\rho_{\text {water }}\right)$ at $1000 \mathrm{~kg} / \mathrm{m}^{3}$. Porosity value $(\varepsilon)$ is calculated by using Eq. 1 [16].

$$
\varepsilon=\frac{\left(m_{\text {wet }}-m_{d r y}\right) \cdot \frac{1}{\rho_{\text {water }}}}{V}
$$

with $\varepsilon$ being the porosity of the media (\%), the $m_{w e t}$ is the mass of the fully saturated specimen $(\mathrm{kg})$, while $m_{d r y}$ is the mass of the RS125. After it is dried $(\mathrm{kg}), \rho_{\text {water }}$ is the water density $\left(\mathrm{kg} / \mathrm{m}^{3}\right)$, and $V$ is the specimen volume $\left(\mathrm{m}^{3}\right)$. 
Table 1 Material specification

\begin{tabular}{|c|c|c|c|c|}
\hline Specimen & Specification & Porosity / \% & $\begin{array}{l}\text { Thermal Conductivity / } \\
\text { W/m } \mathrm{m}^{\circ} \mathrm{C}\end{array}$ & $\begin{array}{l}\text { Mean pores hole } \\
\text { radius / mm }\end{array}$ \\
\hline RS125 & Concrete with river sand aggregate (particle size of $0.125 \mathrm{~mm}$ ) & 19.00 & 0.63 & 0.047 \\
\hline RS250 & Concrete with river sand aggregate (particle size of $0.250 \mathrm{~mm}$ ) & 22.40 & 0.60 & 0.116 \\
\hline FS125 & Concrete with ferrous sand aggregate (particle size of $0.125 \mathrm{~mm}$ ) & 17.80 & 0.72 & 0.121 \\
\hline FS250 & Concrete with ferrous sand aggregate (particle size of $0.250 \mathrm{~mm}$ ) & 20.00 & 0.66 & 0.162 \\
\hline NST & Natural stone & 14.60 & 0.46 & 0.189 \\
\hline
\end{tabular}

3 RESULT AND DISCUSSION

3.1 Surface Temperature Distribution of Specimen

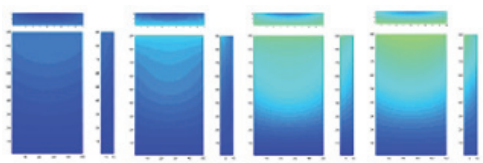

(a) RS125

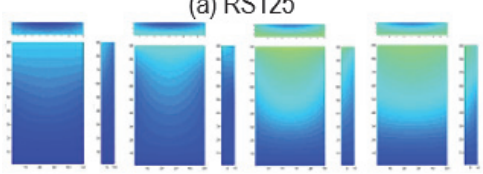

(b) RS250

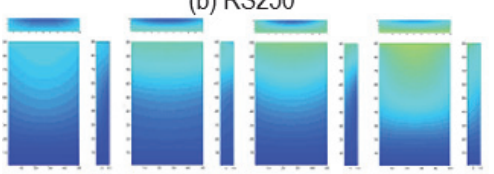

(c) FS125

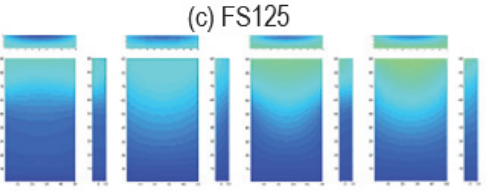

(d) FS250

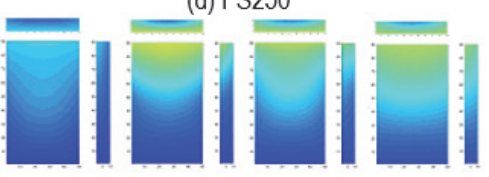

(e) NST

(f) Color temperature range in ${ }^{\circ} \mathrm{C}$

Figure 3 Temperature distribution of RS125t $0 \%, 3.5 \%, 7 \%$ and $10.5 \%$ of water salinity (at radiation intensity of $415.07 \mathrm{~W} / \mathrm{m}^{2}$ )

Fig. 3 shows that the increase in the temperature of the specimen surface was directly proportional to the increase in salinity of the water. The more yellowish color is defined as the higher temperature of the specimen. Specimen with more extensive yellowish color had a better temperature distribution, which resulted in a more significant amount of heated water inside the porous media. Along with a wider high-temperature area inside the specimen, the saltwater absorbed inside the specimen had a larger heating area. Therefore, this made the amount of evaporated water to be more significant in these specimens.

The effect of particle size shows that, along with smaller particle size, the temperature distribution became wider. As seen in Fig. 4, the RS125 and FS125 gained a wider high-temperature zone than RS250 and FS250, respectively. In smaller aggregate particle size, the close contact distance between particles resulted in higher heat conductivity. Therefore, the heat transfer occurred faster than in the concrete with larger particle size.
The NST, a natural rock, had a darker color than the other specimens. The NST allows for greater absorption of radiation energy.

In the three images of the specimen side temperature, it can be seen that the temperature difference between the specimens was not very significant on the higher salt content. The salt content present in each specimen had a significant role in the surface temperature generation of the specimen. The low $C_{p}$ value of $\mathrm{NaCl}$ of $0.853 \mathrm{~J} /(\mathrm{gK})$ affected the temperature of the specimen with a high salt concentration. The parameter of $C_{p}$ value was a constant representing the amount of temperature in which a material can generate on each of the energy inputs. The greater the salt content present in the specimen, the more uniform the temperature value on the specimen surface. The lower $C_{p}$ value of $\mathrm{NaCl}$ made the temperature increase in this material higher than the other materials. This was due to the lower amount of energy required to increase one degree of temperature in $\mathrm{NaCl}$. Thus, the $\mathrm{NaCl}$ could enhance the temperature development besides the influence of thermal conductivity of the specimen.

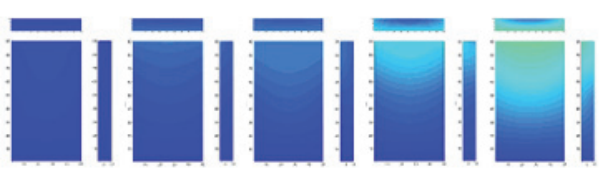

(a) RS125
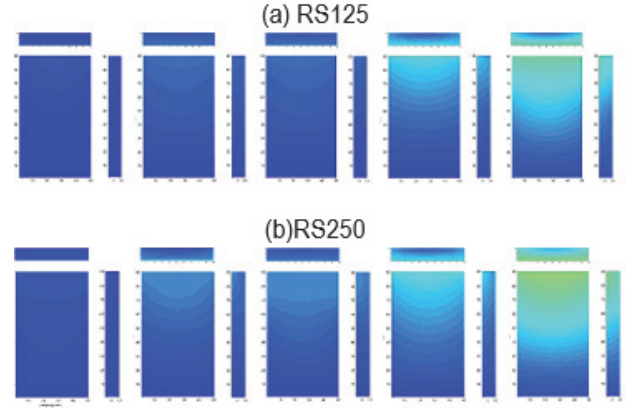

(c)FS125
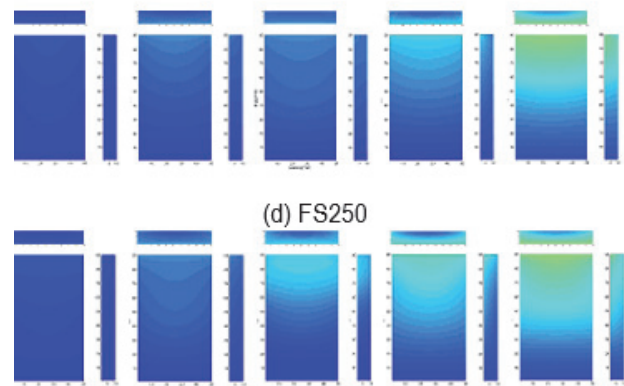

(d) FS250
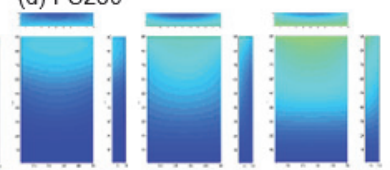

(e) NST

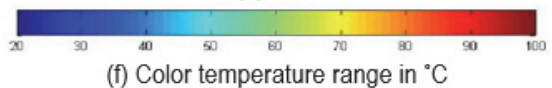

Figure 4 Temperature distribution of specimens at the radiation input of 114.41 $\mathrm{W} / \mathrm{m}^{2}, 179.27 \mathrm{~W} / \mathrm{m}^{2}, 250.11 \mathrm{~W} / \mathrm{m}^{2}, 325.94 \mathrm{~W} / \mathrm{m}^{2}$ and $415.07 \mathrm{~W} / \mathrm{m}^{2}$ 
At higher radiation input, the temperature gained in each specimen was also higher. The data was taken in the salt addition of $3.5 \%$. As seen in Fig. 4, the temperature distribution differences between concrete specimens with ferrous and river aggregate seemed to be higher. Specimen with ferrous sand aggregate (FS125 and FS250) had a wider high-temperature area than the specimen with river sand as the aggregate (RS125 and RS250). These differences were harder to be seen in Fig. 3, where the salt addition played a significant role in temperature distribution that occurred. With the same value of salt added, the material composition had a higher effect. Specimen with ferrous sand aggregate had a high amount of Fe. NST, a natural stone, had a higher amount of Fe than the specimen with river sand. The concrete mixture that has a ratio of 1:2 aggregate and cement composition makes the amount of $\mathrm{Fe}$ in the specimen with river sand have a lower amount of $\mathrm{Fe}$ than the natural stone specimen.

\subsection{Mass Differences of Specimen}

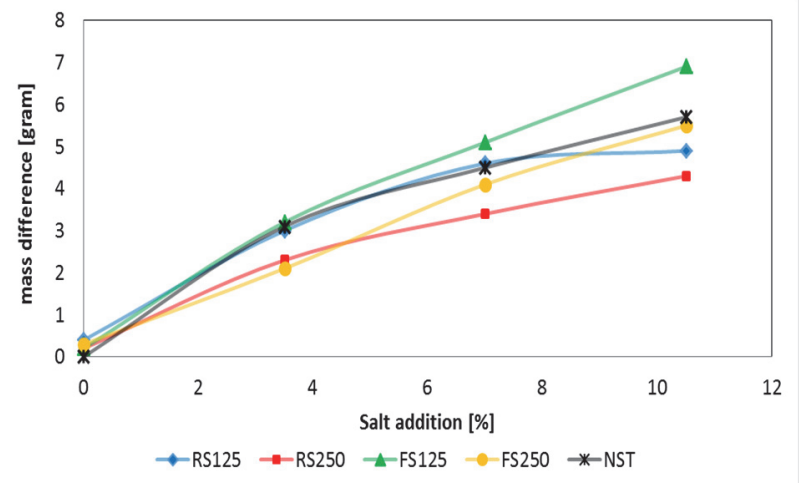

Figure 5 Mass differences of the specimen in each salt addition

Fig. 5 shows the differences in initial mass and the final dried mass of specimen after the experiment. The crystallized salt amount inside the porous media can be expected. As seen in Fig. 5, the mass differences had a higher value in higher salt addition.

The highest mass difference gained in NST in every salt addition varied. The lowest mass difference was in specimen RS250, though it had a higher mass value compared to specimens FS250 at 3.5\% salt addition.

In general, concrete with ferrous sand aggregate had a higher mass difference than concrete with river sand aggregate. This phenomenon caused by the ferrous sand composition in FS125 and FS250 increased the value of thermal conductivity of these specimens. Salt precipitation occurred faster in a higher heat transfer rate. The natural stone specimen had the lowest thermal conductivity value. However, the high mass transfer rate in this specimen resulted in a faster circulation of saltwater that evaporated inside the porous media. The mass differences in NST had the highest value.

The salt precipitation on the surface was validated using macro photograph at some point. The photograph was taken before and after the experiment. Fig. 6 shows the macro photograph of NST. The precipitated salt as seen in Fig. 6 was denoted by the whitish area covering the surface of the specimen. Although the salt crystals in this macro photograph seemed to block the fluids flow, the evaporation process occurred continuously during the experiment. A recent study describes this phenomenon using scanning electron microscopy $[17,18]$. It was found that the salt crystal has a porous structure. The porous structure of precipitated salt was probably the reason for maintaining evaporative fluxes despite the presence of salt at the surface.
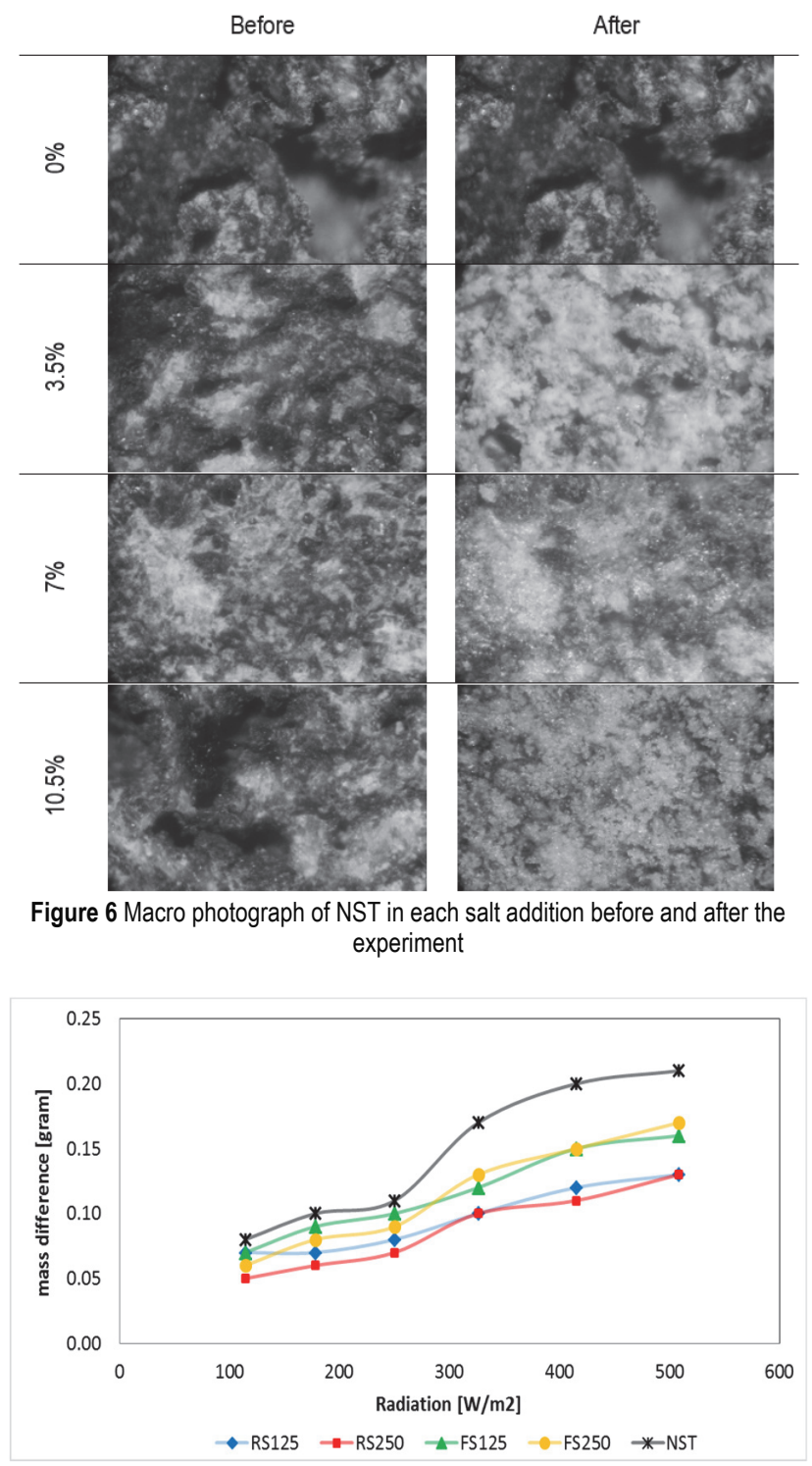

Figure 7 Mass differences of the specimen in each radiation input

Fig. 7 shows the effect of radiation amount towards the mass difference of specimens at $3.5 \%$ of salt addition. Along with higher radiation input, the amount of mass difference was also higher. These values indicate that the amount of crystallized salt inside the specimens was getting higher as the temperature of specimen increased.

As seen in Fig. 5, the tendencies between specimens are similar to the trend in Fig. 4. The concrete with ferrous sand specimens had a higher mass difference value than the concrete with river sand specimens. Thermal conductivities of the specimen played a significant role along with the mass transfer that occurred. 


\subsection{Evaporation Rate of Specimen}

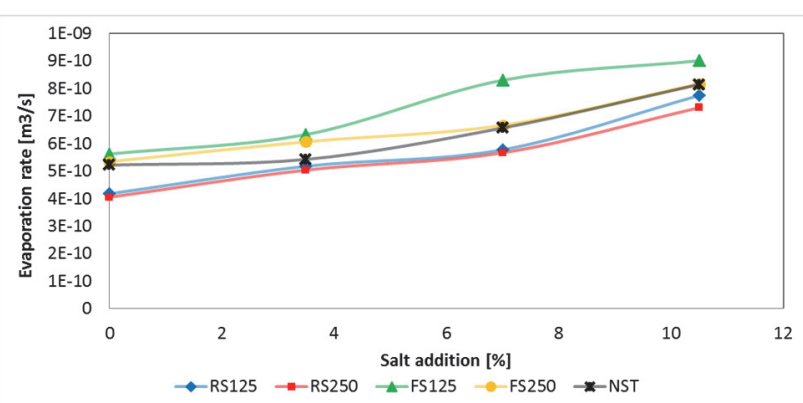

Figure 8 Effects of salt addition towards the evaporation rate of specimens

In contrast to the surface temperature data of specimens that are highly influenced by surface characteristics such as the color of the surface, the evaporation rate was affected by the heat transfer and mass occurring in the body of the specimen. The thermal conductivity parameters had a significant role in the heat transfer process in the whole body of porous media specimens. It appeared that FS125 had the largest evaporation rate compared to other specimens. However, the value of the surface temperature of the NST was relatively high, and the thermal conductivity value of the specimen was quite low. Therefore, the heat distribution generated on NST was not very effective compared to FS125 having the highest thermal conductivity.

Fig. 8 shows that as the salt addition increased, the total evaporation rate was greater in all specimens. The presence of salt content in the FS125 could increase the heat transfer that occurred. From the data in this study, a hypothesis can be drawn that the solar still system with porous media as an absorbent plate with a higher salt concentration (overtime) in the basin can increase the productivity of condensate water. Along with the longer operation time of the solar still, the salt particles left inside the porous media had an increasing number due to the continuous evaporation. As the $\mathrm{NaCl}$ had the lowest amount of required energy to increase its temperature (lower $C_{p}$ value), the higher amount of precipitated salt inside the porous media could enhance the temperature generation of the porous media absorber plate, causing the larger amount of heat provided by the absorber plate to be transferred into saltwater.

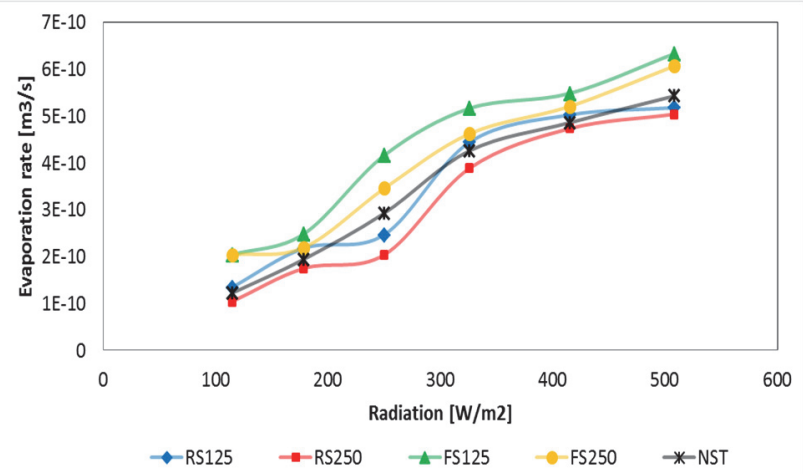

Figure 9 Effects of radiation towards the evaporation rate of specimens

As shown in Fig. 9, the largest evaporation rate gained in FS125 was at every variation of radiation given. High thermal conductivity and proportional values of porosity in
FS125 made this specimen the most capable material to be used as an absorber plate in porous media. At a higher thermal conductivity value of the material, the heat transfer process occurred faster. This caused the saltwater inside FS125 to have a shorter time to reach its evaporation temperature. On the contrary, the specimen with river sand aggregate had the lowest evaporation rate in both varieties of particle size. The darker surface color in NST made the radiation absorbed in this specimen relatively higher than RS125 and RS250.

\section{CONCLUSION}

a. NST which is a natural stone has the highest mass differences with the value of $0.16,0.21,0.23$ and 0.27 gram at $0,3.5 \%, 7 \%$ and $10.5 \%$ salt content. At the surface temperature data, NST also has a higher mean value than other specimens. Natural colors on NST that are darker than other specimens allow for better absorption of radiation energy despite having the lowest thermal conductivity value.

b. Evaporation rate data shows that FS125 has the highest value in which the thermal conductivity value of this specimen is of the highest value as well.

c. The temperature distribution analysis data shows that specimens with ferrous sand aggregate (FS125 and FS250) have a wider high-temperature zone than other specimens.

d. The effects of higher salt addition improve the temperature distribution due to its lower $C_{p}$ value. The crystallized salt could fill the void within the matrix thus resulting in better temperature conductivity on high porosity materials.

e. Higher radiation input causes the temperature value at each specimen to become higher. Therefore, the FS125 which is concrete with $0.125 \mathrm{~mm}$ ferrous sand aggregate has the best capability of porous media in the absorbent plate of solar still application.

\section{ACKNOWLEDGEMENTS}

The authors would like to thank for all the support from Widyagama University and Brawijaya University that provided doctoral study opportunities. We also thank the government for funding the study.

\section{REFERENCES}

[1] Murugavel, K. K., Chockalingama, K. K. S. K., \& Srithar, K. (2008). An experimental study on single basin double slope simulation solar still with thin layer of water in the basin. Desalination, 220, 687-693. https://doi.org/10.1016/j.desal.2007.01.063

[2] Murugavel, K. K., Sivakumar, S., Ahamed, R. J., Chockalingam, K. K. S. K., \& Srithar, K. (2010). Single basin double slope solar still with minimum basin depth and energy. Applied Energy, 87, 514-523. https://doi.org/10.1016/j.apenergy.2009.07.023

[3] Aybar, H., Egeliofglu, F., \& Atikol, U., (2005). Experimental study on an inclined solar water distillation system. Desalination, 180, 285-289. https://doi.org/10.1016/j.desal.2005.01.009

[4] Modi, K. V., Modi, J. G. (2019). Performance of single-slope double-basin solar stills with small pile of wick materials. 
Applied Thermal Engineering, 149, 723-730. https://doi.org/10.1016/j.applthermaleng.2018.12.071

[5] Kaushal A. K., Mittal. M. K., \& Gangacharyulu. D. (2017). An experimental study of floating wick basin type vertical multiple effect diffusion solar still with waste heat recovery. Desalination, 414, 35-45. https://doi.org/10.1016/j.desal.2017.03.033

[6] Fries, N. (2010). Capillary transport processes in porous materials-experiment and model. Bremen: Cuvillier Verlag Gottingen.

[7] Jacob, A., Enzmann, F., Hinz, C., \& Kersten, M. (2019). Analysis of variance of porosity and heterogeneity of permeability at the pore scale. Transport in Porous Media, 130 (3), 867-887. https://doi.org/10.1007/s11242-019-01342-7

[8] Steinhorn, I. (1991). Salt Flux and Evaporation. Notes and Correspondence American Meteorological Society, 16811683.

https://doi.org/10.1175/15200485(1991)021<1681:SFAE>2.0.CO;

[9] Hoque, A., A Abir, A. H., \& Shourov, K. P. (2019). Solar still for saline water desalination for low-income coastal areas. Applied Water Science, 9, 104. https://doi.org/10.1007/s13201-019-0986-9

[10] Kokya, B. A. \& Kokya, T. A. (2006). Proposing a formula for the evaporation measurement from salt water resources. Hydrological processes, 22. https://doi.org/10.1002/hyp.6785

[11] Mickley, M. (2001). Membrane concentrate disposal: Practices and regulation. US Department of Interior.

[12] Dama-Fakir, P. \& Toerien, A. (2010). The effect of salinity on evaporation rates of brines resulting from the treatment of mine water. Golder Associates Africa: ewisa. https://www.docsity.com/pt/dama-fakir-the-effect-ofsalinity-on-evaporation-rates-of-brines/4913377

[13] Zhang, Q., Yang, H., Xiao, X, Wang, H., Yan, L., Shi, Z., Chen, Y., Xu, W., \& Wang, X. (2019). A new self-desalting solar evaporation system based on a vertically oriented porous polyacrylonitrile foam. Journal of Materials Chemistry A, (24), 14620-14628. https://doi.org/10.1039/C9TA03045J

[14] Venkatasamy, M., Sivamani, S., Venkatesan, H., \& Thangaraj M. (2016). Experimental study on productivity enhancement of an improvised inclined solar still. International Journal of Ambient Energy, 105, 326-337. https://doi.org/10.1080/01430750.2017.1280083

[15] Younis, S. M., \& Shakweer, M. H. (2010). Effect of Some Factors on Water Distillation by Solar Energy. Misr J. Ag. Eng., 27 (2), 586-599. https://doi.org/10.21608/mjae.2010.105848

[16] Hansen, R. S., Narayanan, C. S., \& Murugavel, K. K. (2015). Performance analysis on inclined solar still with different new wick materials and wire mesh. Desalination, 358, 1-8. https://doi.org/10.1016/j.desal.2014.12.006

[17] Shokri, N. (2014). Pore-scale dynamics of salt transport and distribution in drying porous media. Physics of Fluids,26, 012106. https://doi.org/10.1063/1.4861755

[18] Norouzi, R. M., Shokri, N., \& Sahimi, M. (2013). Pore scale dynamics of salt precipitation in drying porous media. Phys Rev E Stat Nonlin Soft Matter Phys, 88(3), 032404. https://doi.org/10.1103/PhysRevE.88.032404

\section{Contact information:}

Nova Risdiyanto ISMAIL, Doctoral Student (Corresponding author)

Faculty of Engineering, Brawijaya University, Mechanical Engineering Department,

Ketawanggede, Lowokwaru, Malang City, East Java 65145, Indonesia

E-mail: novarislampung@yahoo.co.id

Sudjito SOEPARMAN, Professor

Faculty of Engineering, Brawijaya University,

Mechanical Engineering Department,

Ketawanggede, Lowokwaru, Malang City, East Java 65145, Indonesia

E-mail: sudjitospn@yahoo.com

Denny WIDHIYANURIYAWAN, Associate Professor

Faculty of Engineering, Brawijaya University,

Mechanical Engineering Department,

Ketawanggede, Lowokwaru, Malang City, East Java 65145, Indonesia

E-mail: Denny_w@ub.ac.id

Widya WIJAYANTI, Associate Professor

Faculty of Engineering, Brawijaya University,

Mechanical Engineering Department,

Ketawanggede, Lowokwaru, Malang City, East Java 65145, Indonesia

E-mail: Widya_dinata@ub.ac.id 